\title{
An Investigation of Executive Functions and Cognitive Emotion Regulation in Labor Children Undergoing Training at Educational Centers
}

\author{
Shamim Razaghi Kashani \\ (MA Student of Educational Psychology)
}

Department of Educational Psychology, Alzahra University, Tehran, Iran

Ali Mashhadi (Associate Professor)

Seyed Mohammad Mahdi Moshirian Farahi, (MA Student of General Psychology)

Department of Psychology, Ferdowsi University of Mashhad, Mashhad, Iran

doi: 10.19044/esj.2017.v13n11p224 URL:http://dx.doi.org/10.19044/esj.2017.v13n11p224

\begin{abstract}
The aim of this study is to determine the comparison of executive functions and cognitive emotion regulation between labor children undergoing training at educational centers and normal children. The sample included 29 male children (mean=9.58, SD=0.50) which was selected from a childcare center. For the control group, 27 third-grade children were selected from a normal primary school (mean=9.40, $\mathrm{SD}=0.50)$. Two questionnaires were used: 1-The extended version of executive function deficiency in everyday life (Barkley, 2011); 2-The child version of cognitive emotion regulation (Garnefski et al., 2007). Part one of this study showed that the scale of executive functions revealed that labor children under training in educational institutions were significantly different in terms of selfdirection and time management and self-organization from normal children. Part two of this study showed that there is a significant reverse relationship between planning refocusing, self-regulation, and time management (r value $<0.05$ ). Moreover, there was a significant reverse relationship between positive reappraisal and spontaneity (r value $<0.01$ ), and a significant negative relationship between positive reappraisal and executive functions ( $r$ value < 0.05). Overall, it can be posited that children undergoing training in educational institutions are not different from normal children in terms of cognitive emotion regulation.
\end{abstract}

Keywords: Executive function, cognitive emotion regulation, labor children 


\section{Introduction}

Executive functions play an important role in cognition and social functions of children (Jacobson, Williford, \& Pianta, 2011). Therefore, executive function is an umbrella term used to describe the processes required for performing deliberate and purposeful activities as well as appropriate social behavior in virtually all daily activity (Snyder, Miyake \& Hankin, 2015). In fact, it refers to a series of cognitive abilities that allow individuals to provide automatic responses to new and complex situations and control their thoughts and behavior (Traverso, Viterbori \& Usai, 2015).

Several theories and concepts about the constitutive skills of executive functions (EF) have been presented with the majority of definitions treating EF as a multidimensional concept. These concepts, however, includes separate yet related components such as attention control, cognitive flexibility, containment, strategic planning, impulse control and self-regulation, which support learning, academic achievement, and behavioral competency (Jacobson et al., 2011).

According to Brown (2006), despite the fact that the definitions of executive function are still evolving, most scholars agree that this term should be used to refer to brain circuits that prioritize, integrate, and regulate other cognitive functions. Moreover, executive functions direct the cognitive functions of the brain and provide regulatory mechanisms (Brown, 2006). EF is composed of a series of cognitive control processes which are chiefly regulated by the frontal cortex of the brain, responsible for low-level processes like perception and motor, and therefore allows selfregulation and self-governing towards predefined goal (Snyder et al., 2015).

Self-regulation is a major adaptive aspect of human behavior which has been widely studied in personality psychology and cognitive psychology (Hofmann, Schmeichel \& Baddeley, 2012). Baumeister, Gailliot, Dewall and Oaten (2006) conceptualized self-regulation as a key personality process through which individuals seek to control their behavior, thoughts, feelings, motives, and task performance.

Emotions play a critical part in the evaluation of experiences and environments and the direction of thoughts and actions. In addition, executive function (EF) and emotion regulation (ER) have received considerable attention not only for their positive relationship with emotional - social functioning of children, but also for their potentially central role in cognitive functioning (Ferrier, Bassett \& Denham, 2014). Therefore, EF and ER are generally treated as dimensions of self (Jahromi \& Stifter, 2007).

Child labor represents one of the major social problems in third world countries, including Iran, which suffer from improper legislation and 
insufficient attention of people and the institution on this issue. Consequently, these children belong to the broader category of street children. This distinction is justified in that some street children have a home to return after doing their work, while some have no place to go. Saleh (2000) described four characteristics of orphans: a) lack of concentration; b) communication problem; c) aggression; and d) dependency. The Municipal Organization defines child labor as "individuals less than 18 years who play a major role in earning their livelihood or providing for their family due to the adverse economic situations of the family so that their withdrawal from work can adversely affect the survival of that family (Organization for Social Services, Welfare and Public Contribution, 2011).

There are many evidences on the relationship between executive functions and emotion regulation (Hoeksma, Oosterlaan \& Schipper, 2004; Kieras, Tobin, Graziano \& Rothbart, 2005). Sudikoff, Bertolin, Lordo and Kaufman (2015) demonstrated the existence of a significant relationship between emotion self-regulation and cognitive executive functions in children. Similarly, Danilewitz (2014) examined the relationship between emotional self-regulation and executive functions by reporting a meaningful relationship between these two variables. However, in general, there is a lack of studies on the direct relationship between cognitive emotion regulation and executive functions. Shokouhi (2001) reported that $40 \%$ of children in correctional facilities came from broken and disrupted families and they lack training with regard to emotion regulation (cited by Khodadadi, 2013). Moreover, some studies have shown that deprivation in the early childhood in terms of the absence of guardian or caretaker would give rise to a host of problems associated with executive functions in children. As a result, this acts as a predictor of stress risk factors in adolescence. For example, the study of Merz and McCall (2011) demonstrated that socio-psychosocial deprivation in early childhood could cause severe executive functions defects in childhood and adolescence. In the same vein, Chugani et al. (2001) revealed that brain malfunction is caused by stress and deprivation in the early childhood, which is usually followed by cognitive and behavioral problems in the future. Moilanen, Shaw and Fitzpatrick (2010) showed that the quality of parent-child relationship in the early childhood was a predictor of self-regulation in adolescence. Nasrolahian, Ebrahim Ghavam, Shabani and Ahmadi (2013) found a significant difference between female-orphaned students who had participated in cognitive and metacognitive courses and those who had not. Hostinar, Stellern, Schaefer, Carlson and Gunnar (2012) revealed that orphaned children held in Childcare centers, if subjected to low-quality physical and social care, would have deteriorated executive functions. In 
general, previous researches have examined the role and significance of the early childhood in predicting emotional and cognitive problems in later times. Nevertheless, the effect of long-term intervention (e.g. school education) on mitigating the negative effect of poor supervision and negligence during childhood needs to be investigated.

\section{Method}

This research consists of two studies. The first is a descriptive study with a causal-comparative method, while the second is a correlational study.

\section{Participants}

The study population consists of all street children in Tehran. The sample, which was selected from a childcare center, included 29 male children. For the control group, 27 third-grade children were selected from a normal primary school using available sampling method. After the consent letters accepted by participants, parents and childcare center were employed as part of this study.

\section{Tools}

For the study of executive functions and their comparison in labor and normal children, the extended version of executive function deficiency in everyday life was used. Therefore, this questionnaire was designed in 2011 by Barkley for children aged 6 to 17 years. The items in the questionnaire should be answered by the main guardian of children, who is usually their parent, based on their behavior during the past six (6) months. This test contains 70 items divided into four sections, which covers five components of executive functions in the daily life of children.

Furthermore, these components include self-direction and time management, self-organization, self-restraint, self-motivation, and selfregulation. Each item is assigned a score of 1 to 4 and the total score of participants in each section was calculated and then standardized between 0 and 100 with regard to table of normal age and gender. Moreover, the scores of executive functions based on the total scores of 5 sections, the signs of executive functions based on the number of items with a score of 3 or 4 , and symptoms of attention deficit hyperactivity disorder (ADHD) based on the total score of items 5, 20, 21, 23, 27, 35, 47, 51, 59, and 68 were computed. After then, it was standardized in the range of 0 and 100 for each participant based on the table of normal age and gender. The acceptable validity and reliability of this test has been shown with a Cronbach's alpha coefficient of 0.95 to 0.97 being reported for all five sections. The reported validity of this test was in the range of 0.73 and 0.82 for subscales, and 0.82 for executive functions (Barkley, 2011). 
The child version of cognitive emotion regulation (CERQ-K) is a multidimensional questionnaire which is utilized to identify the coping strategies of children after experiencing negative events or accidents. Unlike other coping questionnaires that fail to make a definite distinction between an individual's thoughts and real-life actions, this questionnaire offers a posttraumatic analysis of one's thoughts after encountering an adverse experience or damaging events in form of a 36-item self-report instrument. Subsequently, CERQ-K has a strong empirical and theoretical foundation, and is composed of 9 subscales including Self-blame, Other blame, Acceptance, Planning refocusing, Positive refocusing, Rumination or focus on thought, Positive reappraisal, Putting into perspective, and Catastrophizing.

The score of each subscale ranges from 1 (almost never) to 5 (almost always). Each subscale consists of four items. The total score of each subscale is computed by adding up the scores of item. Thus, the score range of each subscale is between 4 and 20 . Higher scores in each subscale indicate the greater use of relevant strategies in dealing with stressful and adverse life events (Garnefski, Rieffe, Jellesma, Terwogt, \& Kraaij, 2007). Mashhadi, Hasani and Mirdouraghi (2012) opine that the estimated Cronbach's alpha coefficient was 76.0 for self-blame, 0.78 for acceptance, 0.81 for rumination, 0.77 for positive refocusing, 0.76 for planning refocusing, 0.81 for positive reappraisal, 0.79 for putting into perspective, 0.76 for catastrophizing, 0.85 for other blame subscales, and 0.86 for the total scale. Thus, the range of the maximum correlation of item groups is greater than 0.4. The analysis of factor structure of this questionnaire using exploratory factor analysis supported the 9-factor pattern of CERQ, which explained $68 \%$ of variance. The results of factor analysis also indicated the desirable fitness of the items. In addition, the pattern of correlation coefficient between subscales and concurrent criterion validity of the questionnaire and that of multidimensional anxiety scale of children and child depression scale indicated the desirable reliability of this scale.

\section{Procedure}

In the first step, the study population which was chosen encompassed Street children aged 8 to 10 years and ordinary children of the same age. The sample was selected from a primary school out of which 30 male third-grade students were chosen to participate in the study. The labor children were also selected from a childcare center using available sampling method.

The 36-item cognitive emotion regulation and 72-item executive functions questionnaire were given to the teachers of normal students to be distributed among and completed by parents. Finally, it is to be submitted to 
teachers again. At the end, three participants from the normal group and one from the labor-children group failed to answer the questionnaire. As a result, they were therefore excluded from the study. Data analysis was performed using SPSS22.

\section{Data Analyses}

After completing the questionnaire of executive functions and cognitive emotion regulation, data were keyed into SPSS22 software. In this study, descriptive indicators (mean and standard deviation) and inferential statistics were used for data interpretation. The statistical inference index included correlation and MANOVA test. First, research variables were compared in two groups of normal and labor children using MANOVA test. Then, the Pearson correlation test was performed to determine the associated variables.

\section{Results}

The data were analyzed using SPSS22 software. Participants included normal and labor children studying at primary schools. The mean age of normal children was 9.40 with $\mathrm{SD}=0.50$, while the mean age of labor children was 9.58 with $\mathrm{SD}=0.50$.

The results of MANOVA test with regard to the scale of executive action revealed that labor children under training in educational institutions were significantly different in terms of self-direction and time management and self-organization from normal children. However, the two groups were not significantly different with respect to other variables of executive functions. Additionally, the findings did not show any significant difference between labor children under training in educational institutions, and normal children in terms of cognitive emotion regulation.

The results of Pearson correlation test suggested the existence of a significant reverse relationship between planning refocusing, self-regulation, and time management ( $\mathrm{r}$ value $<0.05$ ). Moreover, there was a significant reverse relationship between positive reappraisal and spontaneity (r value $<0.01$ ), and a significant negative relationship between positive reappraisal and total score of executive functions (r value $<0.05$ ).

\section{Discussion and Conclusion}

The aim of this study was to compare executive functions and cognitive emotion regulation in labor children under training in educational centers and normal children. The findings of the study indicated a significant difference between the two groups in terms of self-regulation, time management, and self-organization. Bauer, Hanson, Pierson, Davidson and Pollak (2009) showed that children deprived of early childhood 
experiences were more likely to suffer from memory malfunction and defective planning. This is such that experiences dependent on others tend to exert a huge impact on cerebral functions and consequently executive functions.

Similarly, Bos, Fox, Zeanah and Nelson Iii (2009) revealed that people who were deprived of care during their life were more likely to develop memory dysfunction and defective executive functions. The study of McDermott et al. (2013) demonstrated that children who had experienced deprivation in their early childhood were defective in executive functions.

With regard to the previous findings on executive functions, this study supports part of previous findings (in terms of time management and self-organization). Nevertheless, deficiency in all executive functions was not approved by the present study. The focus of this study was on poorly supervised labor children under training. In addition, the defects of these children could be partly attributed to the effect of school teachings on moderating executive function problems in this group of children.

Furthermore, the findings of this study did not show any significant difference between the two groups in terms of cognitive emotion regulation. Audet (2003) studied the difficulty of self-regulation on guardianless Romanian children, and found that biological effects of the early childhood were important in later periods of childhood. Thus, it could lead to selfregulation problem in children. Tottenham et al. (2010) used neuroimaging approach to investigate guardianless children kept in childcare institutions. In this study, they used MRI to analyze brain structure in amygdala and hippocampus.

Their findings suggested that early childhood stress could damage emotional behaviors related to the amygdala. In this respect, the results of this study are not consistent with previous findings. The main contribution of Tottenham et al. (2010) was the inclusion of neuroimaging, which gives it the edge over this study. Accordingly, more emphasis on neurological analyses was further supported by empirical studies.

In sum, this research consisted of two parts. The first part involved a comparison of executive functions in labor children under training in educational institutions and ordinary children, while the second part drew a comparison between cognitive emotion regulation in labor children undergoing training in educational institutions and normal children.

This study also explored the correlation between two variables of executive function and cognitive emotion regulation. The results of correlation study revealed a significant reverse relationship between planning refocusing, self-regulation, and time management. Moreover, there was a significant reverse relationship between positive reappraisal and spontaneity. 
Also, they were a significant negative relationship between positive reappraisal and the total score of executive functions. The findings of the Schmeichel and Tang (2015) stressed the pivotal role of cognitive and executive functions in emotional processes. Additionally, the study of Sudikoff, Bertolin, Lordo and Kaufman (2015) on the relationship between executive functions and cognitive emotion regulation in healthy children indicated the existence of a significant relationship between these two variables.

Finally, it can be posited that children undergoing training in educational institutions are not different from normal children in terms of cognitive emotion regulation. This reflects the success of the educational institutions of Tehran in training these children. In this context, the findings of the study showed that labor children undergoing training were still defective in executive functions. This, therefore, indicates the important role of a guardian in the early childhood as it exerts a greater effect on executive functions compared to cognitive emotion regulation.

Furthermore, this study has a number of limitations. The most important of them was data collection instrument, i.e. questionnaire, completed by children's caregivers. This was primarily due to the lack of research facilities and the difficulty in obtaining necessary permits to visit these institutions to apply instruments such as stroop test and cognitive paradigm tools. To gain deeper insight about labor children, it was recommended to examine the relationship between emotional and cognitive variables. Also, a causal-comparative analysis of these two variables using neuropsychological instruments should be conducted.

\section{Acknowledgement}

The present study was administered by the authors in the absence of any financial supports by any organization. All procedures performed in studies involving human participants were in accordance with the ethical standards of the department of psychology's research committee at Ferdowsi University of Mashhad, Iran and with the 1964 Helsinki declaration and its later amendments or comparable ethical standards.

\section{References}

1. Audet, K. (2003). Attentional and self-regulatory difficulties of Romanian orphans 10 years after being adopted to Canada: A Longitudinal Study. M.A Thesis, Simon Fraser University.

2. Barkley, R.A. (2011). Barkley deficits in executive functioning scale (BDEFS). New York: Guilford Press.

3. Bauer, P.M., Hanson, J.L., Pierson, R.K., Davidson, R.J., Pollak, S.D. (2009). Cerebellar volume and cognitive functioning in children 
who experienced early deprivation. Biol Psychiatry, 66(12), 1100-6. doi: 10.1016/j.biopsych.2009.06.014.

4. Baumeister, R. F; Gailliot, M; Dewall, C. N \& Oaten, M. (2006). Self-Regulation and Personality: How Interventions Increase Regulatory Success, and How Depletion Moderates the Effects of Traits on Behavior. Journal of Personality, 74(6), 1773-1802. DOI: 10.1111/j.1467-6494.2006.00428.x.

5. Bos, K.J., Fox, N., Zeanah, C.H., Nelson Iii, CA. (2009). Effects of early psychosocial deprivation on the development of memory and executive function. Front Behav Neurosci, 3, 16. doi: 10.3389/neuro.08.016.2009.

6. Brown, T. E. (2006). Executive Functions and Attention Deficit Hyperactivity Disorder: Implications of two conflicting views. International Journal of Disability, Development and Education. 53(1), 35-46. DOI: 10.1080/10349120500510024.

7. Chugani, H.T; Behen, M.E; Muzik, O; Juhász, C; Nagy, F \& Chugani, D.C. (2001). Local brain functional activity following early deprivation: a study of postinstitutionalized Romanian orphans. Neuroimage, 14(6), 1290-1301. doi:10.1006/nimg.2001.0917.

8. Danilewitz, J. (2014). The Relationship between emotion regulation and executive functioning after sleep restriction in healthy preschool children. Honors Psychology Thesis Department of Psychology, The University of Western Ontario London, Ontario Canada.

9. Ferrier, D.E., Bassett, H. H \& Denham S.A. (2014). Relations between executive function and emotionality in preschoolers: Exploring a transitive cognition-emotion linkage. Front Psychol, 5, 487. doi:10.3389/fpsyg.2014.00487.

10. Garnefski, N., Rieffe, C., Jellesma, F., Terwogt, M. M., \& Kraaij, V. (2007). Cognitive emotion regulation strategies and emotional problems in 9 - 11-year-old children: the development of an instrument. Eur Child Adolesc Psychiatry, 16(1), 1-9. doi: 10.1007/s00787-006-0562-3

11. Hoeksma, J. B; Oosterlaan, J \& Schipper, E. M. (2004). Emotion regulation and the dynamics of feelings: A conceptual and methodological framework. Child Development, 75(2), 354-360. DOI: 10.1111/j.1467-8624.2004.00677.x.

12. Hofmann, W., Schmeichel, B. J., \& Baddeley, A. D. (2012). Executive functions and self-regulation. Trends in cognitive sciences, 16(3), 174-180.

13. Hostinar, C. E., Stellern, S. A., Schaefer, C., Carlson, S. M., \& Gunnar, M. R. (2012). Associations between early life adversity and executive function in children adopted internationally from 
orphanages. Proc Natl Acad Sci U S A, 109 Suppl 2, 17208-17212. doi: 10.1073/pnas.1121246109

14. Jacobson, L. A; Williford, A. P \& Pianta, R. C. (2011). The Role of Executive Function in Children's Competent Adjustment to Middle School. Child Neuropsychol. 17(3), 255-280. doi: 10.1080/09297049.2010.535654.

15. Jahromi, L. B \& Stifter, C. A. (2007). Individual differences in the contribution of maternal soothing to infant distress reduction. Infancy, 11(3), 255-269. DOI: 10.1111/j.1532-7078.2007.tb00226.x.

16. Khodadadi, S. T. (2013). The effectiveness of TAME educational training on reducing aggression and improving cognitive emotion regulation in orphan male adolescents. MA thesis in Clinical Psychology, Faculty of Education and Psychology, Ferdowsi University of Mashhad, Mashhad, Iran.

17. Kieras, J. E; Tobin, R. M; Graziano, W. G \& Rothbart, M. K. (2005). You can't always get what you want: Effortful control and children's responses to undesirable gifts. Psychological Science, 16(5), 391396.

18. Mashhadi, A., Hasani, J \& Mirdouraghi, F. (2012). Factor structure, reliability and validity of Persian version of the cognitive emotion regulation questionnaire-children form (CERQ-K-P). Journal of Fundamentals of Mental Health, 14(3), 246-259.

19. McDermott, J.M., Troller-Renfree, S., Vanderwert, R., Nelson, C.A., Zeanah, C.H., Fox, N.A. (2013). Psychosocial deprivation, executive functions, and the emergence of socio-emotional behavior problems. Front Hum Neurosci, 7, 167. doi: 10.3389/fnhum.2013.00167.

20. Merz, E.C \& McCall, R.B. (2011). Parent ratings of executive functioning in children adopted from psychosocially depriving institutions. J Child Psychol Psychiatry, 52(5), 537-546. doi: 10.1111/j.1469-7610.2010.02335.x.

21. Moilanen, K.L; Shaw, D.S \& Fitzpatrick, A. (2010). Self-Regulation in Early Adolescence: Relations with Mother-Son Relationship Quality and Maternal Regulatory Support and Antagonism. J Youth Adolesc, 39(11), 1357-1367. doi: 10.1007/s10964-009-9485-X.

22. Nasrollahian Mojarad, S; EbrahimiGavam, S; Shabani, S \& Ahmadi G. T. (2013). Studying the Effects of Teaching Cognitive and Meta Cognitive. Strategies on Self-regulation of Orphan Girl Students. Social and Behavioral Sciences, 84, 1745 - 1749. doi:10.1016/j.sbspro.2013.07.019.

23. Organization for Social Services, Welfare and Public Contribution. (2011). Return instructions and identifying street children, Tehran Municipality. 
24. Saleh, A. (2000). A comparative study on cognitive, behavioral and social characteristics of orphan and street children of Tehran City. M.A. dissertation submitted to the faculty of human science of Tarbyat Modares University.

25. Schmeichel, B.J., Tang, D. (2015). Individual Differences in Executive Functioning and Their Relationship to Emotional Processes and Responses. Current Directions in Psychological Science, 24(2), 93-98. doi: 10.1177/0963721414555178

26. Snyder, H. R., Miyake, A., \& Hankin, B. L. (2015). Advancing understanding of executive function impairments and psychopathology: bridging the gap between clinical and cognitive approaches. Front Psychol, 6, 328. doi: 10.3389/fpsyg.2015.00328

27. Sudikoff, E.L., Bertolin, M., Lordo, D.N., Kaufman, D.A.S. (2015). Relationships between Executive Function and Emotional Regulation in Healthy Children. Journal of Neurology and Psychology, S(2):8.

28. Tottenham, M., Hare, T.A., Quinn, B.T., McCarry, T.W., Nurse, M., Gilhooly, T., ... et al. (2010). Prolonged institutional rearing is associated with atypically larger amygdala volume and difficulties in emotion regulation. Dev Sci, 13(1), 36. doi: 10.1111/j.14677687.2009.00852.x

29. Traverso, L., Viterbori, P., \& Usai, M. C. (2015). Improving executive function in childhood: evaluation of a training intervention for 5-year-old children. Front Psychol, 6, 525. doi: 10.3389/fpsyg.2015.00525 
Tables

Table 1. Descriptive indexes of executive functions in labor and normal children

\begin{tabular}{|c|c|c|c|c|}
\hline \multirow[t]{2}{*}{ Variables } & \multicolumn{2}{|c|}{ Normal Children } & \multicolumn{2}{|c|}{ Labor Children } \\
\hline & Mean & $\begin{array}{l}\text { Standard } \\
\text { Deviation }\end{array}$ & Mean & $\begin{array}{l}\text { Standard } \\
\text { Deviation }\end{array}$ \\
\hline $\begin{array}{l}\text { Time } \\
\text { management and } \\
\text { self-direction }\end{array}$ & 20.22 & 5.43 & 24.00 & 6.91 \\
\hline Self-organization & 21.33 & 7.29 & 26.72 & 7.18 \\
\hline Self-restraint & 23.85 & 7.43 & 20.68 & 6.69 \\
\hline Self-motivation & 22.44 & 7.05 & 24.89 & 6.10 \\
\hline $\begin{array}{l}\text { Emotional self- } \\
\text { regulation }\end{array}$ & 30.40 & 10.36 & 29.24 & 7.61 \\
\hline $\begin{array}{l}\text { Total score of } \\
\text { executive } \\
\text { functions }\end{array}$ & 118.25 & 32.63 & 125.55 & 26.90 \\
\hline
\end{tabular}

Table 2. Descriptive indexes of cognitive emotion regulation in labor and normal children

\begin{tabular}{|l|l|l|l|l|}
\hline \multirow{2}{*}{ Variables } & \multicolumn{2}{l|}{ Normal Children } & Labor Children \\
\cline { 2 - 5 } & Mean & $\begin{array}{l}\text { Standard } \\
\text { Deviation }\end{array}$ & Mean & $\begin{array}{l}\text { Standard } \\
\text { Deviation }\end{array}$ \\
\hline Self-blame & 8.85 & 3.33 & 9.86 & 3.53 \\
\hline Acceptance & 8.74 & 3.20 & 9.65 & 3.53 \\
\hline Rumination & 11.77 & 4.06 & 11.41 & 3.66 \\
\hline Positive refocusing & 12.29 & 4.60 & 12.72 & 3.39 \\
\hline Planning refocusing & 13.7 & 3.29 & 13.37 & 3.24 \\
\hline Positive reappraisal & 13.11 & 3.51 & 11.55 & 3.90 \\
\hline $\begin{array}{l}\text { Putting into } \\
\text { perspective }\end{array}$ & 12.92 & 3.72 & 11.75 & 3.65 \\
\hline Catastrophizing & 9.11 & 2.97 & 9.75 & 3.07 \\
\hline Other blame of & 8.00 & 3.05 & 8.20 & 3.52 \\
\hline $\begin{array}{l}\text { Total score } \\
\text { cognitive emotion } \\
\text { regulation }\end{array}$ & 98.51 & 15.33 & 98.31 & 17.45 \\
\hline
\end{tabular}

Table 3. Results of MANOVA in executive functions and cognitive emotion regulation

\begin{tabular}{|c|c|c|c|c|}
\hline Variable & Mean Square & Df & $\mathrm{F}$ & Significant \\
\hline $\begin{array}{l}\text { Time } \\
\text { management and } \\
\text { self-direction }\end{array}$ & 199.54 & 1 & 5.11 & 0.02 \\
\hline Self-organization & 406.33 & 1 & 7.75 & 0.007 \\
\hline Self-restraint & 139.81 & 1 & 2.80 & 0.100 \\
\hline Self-motivation & 84.07 & 1 & 1.94 & 0.169 \\
\hline $\begin{array}{ll}\text { Emotional self- } \\
\text { regulation }\end{array}$ & 19.01 & 1 & 0.23 & 0.632 \\
\hline $\begin{array}{l}\text { Total score of } \\
\text { executive } \\
\text { functions }\end{array}$ & 743.57 & 1 & 0.83 & 0.364 \\
\hline Self-blame & 14.26 & 1 & 1.31 & 0.256 \\
\hline Acceptance & 11.69 & 1 & 1.02 & 0.317 \\
\hline Rumination & 1.85 & 1 & 0.12 & 0.726 \\
\hline $\begin{array}{l}\text { Positive } \\
\text { refocusing }\end{array}$ & 2.55 & 1 & 0.15 & 0.692 \\
\hline
\end{tabular}




\begin{tabular}{|l|l|l|l|l|}
\hline $\begin{array}{l}\text { Planning } \\
\text { refocusing }\end{array}$ & 1.47 & 1 & 0.13 & 0.712 \\
\hline $\begin{array}{l}\text { Positive } \\
\text { reappraisal }\end{array}$ & 34.00 & 1 & 2.45 & 0.123 \\
\hline $\begin{array}{l}\text { Putting into } \\
\text { perspective }\end{array}$ & 19.05 & 1 & 1.40 & 0.241 \\
\hline Catastrophizing & 5.86 & 1 & 0.63 & 0.428 \\
\hline Other blame score of & 0.59 & 1 & 0.04 & 0.827 \\
\hline $\begin{array}{l}\text { Total sol } \\
\text { cognitive } \\
\text { emotion } \\
\text { regulation }\end{array}$ & 1 & 0.00 & 0.963 \\
\hline
\end{tabular}

Table 4. The results of correlation between executive functions and cognitive emotion regulation

\begin{tabular}{|l|l|l|l|l|l|l|}
\hline Variables & $\begin{array}{l}\text { Time } \\
\text { management } \\
\text { and self- } \\
\text { direction }\end{array}$ & $\begin{array}{l}\text { Self- } \\
\text { organization }\end{array}$ & $\begin{array}{l}\text { Self- } \\
\text { restraint }\end{array}$ & $\begin{array}{l}\text { Self- } \\
\text { motivation }\end{array}$ & $\begin{array}{l}\text { Emotional } \\
\text { self- } \\
\text { regulation }\end{array}$ & $\begin{array}{l}\text { Total } \\
\text { score of } \\
\text { executive } \\
\text { functions }\end{array}$ \\
\hline Self-blame & 0.01 & 0.09 & 0.07 & 0.10 & -0.02 & 0.05 \\
\hline Acceptance & -0.12 & -0.01 & 0.15 & 0.26 & 0.11 & 0.09 \\
\hline Rumination & -0.08 & -0.12 & 0.00 & -0.08 & -0.07 & -0.09 \\
\hline $\begin{array}{l}\text { Positive } \\
\text { refocusing }\end{array}$ & -0.21 & -0.09 & -0.22 & -0.20 & -0.18 & -0.22 \\
\hline $\begin{array}{l}\text { Planning } \\
\text { refocusing }\end{array}$ & $-0.27^{*}$ & -0.09 & -0.01 & -0.09 & -0.19 & -0.16 \\
\hline $\begin{array}{l}\text { Positive } \\
\text { reappraisal }\end{array}$ & -0.16 & -0.22 & -0.25 & $-0.37 * *$ & -0.24 & -0.31 \\
\hline $\begin{array}{l}\text { Putting into } \\
\text { perspective }\end{array}$ & -0.10 & 0.00 & 0.16 & 0.05 & 0.09 & 0.06 \\
\hline Catastrophizing & 0.19 & 0.18 & 0.09 & 0.06 & 0.04 & 0.14 \\
\hline Other blame & 0.13 & -0.02 & 0.17 & 0.19 & 0.05 & 0.12 \\
\hline $\begin{array}{l}\text { Total score of } \\
\text { cognitive } \\
\text { emotion } \\
\text { regulation }\end{array}$ & -0.14 & -0.07 & 0.02 & -0.03 & -0.09 & -0.08 \\
\hline
\end{tabular}

